\title{
The HANS KAI Project: a community-based approach to improving health and well-being through peer support
}

\author{
Alexandra Henteleff, MEd; Helena Wall, MEd
}

This original mixed methods research article has been peer reviewed.

Tweet this article

\begin{abstract}
Introduction: HANS KAI is a unique health promotion intervention to improve participants' health by focussing on interrelated chronic disease prevention behaviours through peer support and strengthening of social support networks. The study objective was to determine the effectiveness of HANS KAI in an urban Canadian setting.

Methods: We used a mixed methods intervention research design that involved multiple sites from November 2010 to April 2015. Data was obtained from participant surveys as well as in-person interviews at zero, 6, 12 and 24 months. Participants met in groups at least once a month during the research period, to self-monitor health indicators, prepare and share a healthy snack, participate in a physical activity, set a healthy lifestyle goal (optional) and socialize.
\end{abstract}

Results: There were statistically significant mental health improvements from pre- to post-program, and $66 \%$ of the participants described specific behaviour changes as a result of HANS KAI participation. Additional positive health impacts included peer support; acquiring specific health knowledge; inspiration, motivation or accountability; the empowering effect of monitoring one's own health indicators; overcoming social isolation and knowing how to better access services.

Conclusion: The need to identify innovative ways to address chronic disease prevention and management has been the driver for implementing and evaluating HANS KAI. While further research will be required to validate the present findings, it appears that HANS KAI may be an effective approach to create environments that empower community members to support each other while promoting healthy lifestyle choices and detecting early changes in health status.

Keywords: health promotion, chronic disease, prevention, social support, peer group, self-help groups, peer support

\section{Introduction}

This paper reports on an innovative community-based health promotion intervention offered by a Manitoba-based health care co-operative that explored the relationship between peer support and perceptions of wellness. Peer support was defined as "a system of giving and receiving help founded on key principles of respect, shared responsibility, and mutual agreement of what is helpful." ${ }^{1, p .137}$ It is about understanding another's situation empathically through shared experience. As trust in their relationship builds, people are able to respectfully challenge each other, try out new behaviours with one another and move beyond previously held self-concepts. This is referred to as mutual empowerment. ${ }^{1}$

Peer support has been used to help individuals adjust to life-transitioning changes, such as the birth of a child, significant losses or long-term disabilities / chronic diseases, and in health promotion initiatives, including support for health behaviour changes. ${ }^{2-4}$ Ford et al. stated that peer support programs "are emerging as highly effective and empowering ways for people

\section{Highlights}

- Innovative methods are needed to address chronic disease prevention and management in socioeconomically challenged communities.

- HANS KAI harnesses peer support to empower community members to support each other while promoting healthy lifestyle choices that address interrelated chronic disease prevention behaviours and detecting early health changes.

- HANS KAI is unique as it focusses on health where most peer support interventions are disease specific.

- Participation in HANS KAI resulted in statistically significant improvement in mental health scores.

- Participants also reported decreased social isolation, healthy behaviour change, increased knowledge of and access to services, and empowerment from self-monitoring personal health indicators.

to manage health issues" ${ }^{5, p .5507}$ in a socially supportive context. We found no documented examples in the literature of Canadian community-based initiatives using a peer support model to create social networks to support personal wellness that did not primarily have a diseasespecific focus.

\section{Intervention}

HANS KAI is a unique health promotion intervention to improve the health of participants through peer support and strengthening of social support networks. HANS KAI is modelled after a han, a style 
of health management started by Japanese health cooperatives in the mid-1950s to encourage people to take responsibility for their own health and to promote preventive medicine. ${ }^{6}$ In Japanese, han means "group" and kai means "assembly" or "meeting." The han group approach was intended to take the burden off primary care, and encourage peer support and personal empowerment. ${ }^{6}$ HANS KAI groups (HANS groups) typically consist of about 10 members matched on characteristics such as age, community area and availability. Integral to this intervention is the idea that people who spend time together and monitor their health will live longer, healthier lives. ${ }^{7}$

Social learning theory ${ }^{8}$ and empowerment theory ${ }^{9}$ form the theoretical foundation for the HANS KAI intervention. Social learning theory explains human behaviour as a continuous interaction between cognitive, behavioural and environmental influences: people learn through observing others' behaviour and attitudes as well as the outcomes of the behaviour. ${ }^{7}$ Like Bandura's social learning theory, ${ }^{8}$ empowerment includes the concept of self-efficacy, where perceptions of competence, personal control and positive self-image support individuals to think positively about their ability to effect change and have mastery over issues. ${ }^{9}$ The empowerment approach "redefines the professional's role ... to one of collaborator ... [where] participants have an active role in the change process." ${ }^{\text {,p.44-45 }}$

A review of the literature did not produce any research on the effectiveness of peer support groups to improve the health of participants without a specific disease focus. We undertook this research project to implement and evaluate the effectiveness of HANS KAI in an urban Canadian setting. In our program design, peers in HANS groups were fellow group members. Participants would attend a "Health School" at enrolment to receive baseline knowledge about a variety of health topics as well as training on how to take their own health measures and work independently as a group. Participants then would meet in small groups at least once a month for about two hours to learn about health topics from each other and from health care providers, participate in physical exercise, make and share a nutritious snack, monitor and record their health measures in logbooks, and have time to socialize.

\section{Setting}

NorWest Co-op Community Health (NorWest) is committed to engaging its community in cooperative health and wellness with a vision of people taking control of their health. NorWest is situated in the Inkster community of Winnipeg, a socioeconomically challenged community where $20 \%$ of families live below the low-income cutoff. ${ }^{10}$ The area lacks recreational facilities, and, in a 2008 report, $86 \%$ of residents felt that social support was key to changing behaviours related to eating and physical activity, and that it was the most important factor for joining healthy lifestyle programs. ${ }^{11}$ NorWest decided that HANS KAI matched their vision, mission and values, and wanted to see if implementing HANS KAI was feasible and beneficial.

\section{Research objectives}

The purpose of this research study was to determine if structured, peer-led community groups could be successfully initiated within an urban Canadian context and have a positive impact on participant health and well-being. The objectives of the intervention were to:

1. create social and peer support networks to increase participants' ability to make healthier lifestyle choices to support personal wellness, empower participants to take action to improve their health and develop connections with others to reduce social isolation;

2. increase participants' awareness of the connection between personal wellness, healthy lifestyle choices, healthy weights and those factors within and outside of their control;

3. maintain or improve measurable health indicators; and

4. increase access to primary care services and other community programs/ services.

\section{Methods}

\section{Research design}

We used a participatory community-based design, involving community members during each stage of the research. A community board sought an investigator through a solicitation of interest (SOI), to explore the impact of participation in a HANS group on a range of health outcomes. The community board reviewed the responses to the SOI, selected, then met with the research team and had input in the final design. NorWest staff had the primary role to support the implementation of HANS and work closely with the researchers during the research processes. Members in pre-existing community groups participated in piloting the HANS KAI model and provided invaluable feedback to guide the finalization of the research tools. Preliminary results were shared via presentations to the community board and the HANS groups, and at community events and the NorWest AGM in June 2017.

A mixed methods intervention research design, involving multiple sites, was used as its flexible form of inquiry captured multiple perspectives about, and promoted a more complete understanding of, the intervention experience. ${ }^{12}$

Quantitative pre-test, post-test data were obtained from participant surveys and data were entered into a purpose-built database. Qualitative findings were obtained through one-on-one interviews with participants. Data collection took place from November 2010 to April 2015. The survey and interviews were done at 0 (baseline), 6, 12 and 24 months. The study received written approval from the University of Manitoba's Education/Nursing Research Ethics Board, protocol \#E2010:102.

\section{Recruitment}

A variety of recruitment techniques were used, including community or workplace presentations; mail-outs to NorWest clients; health care provider referrals; posters located in areas where people congregate (grocery stores, pharmacies, community centres and medical clinics); and in-person recruitment through HANS awareness presentations at community events and groups. Inclusion criteria were: resident of the Inkster or Seven Oaks community areas of Winnipeg, 18 years of age or over, able to speak and read English, and be in relatively good health, including individuals with chronic conditions as long as the condition was stable.

A targeted approach was used to enrol participants who were socially isolated and/or economically challenged such as seniors, new mothers and new Canadians. Individuals who wished to participate in HANS had to complete an application form and were then assigned into either 
pre-existing or new groups, according to age, community area and availability.

Group participants attended a HANS KAI "Health School," which consisted of six 2-hour face-to-face sessions to help participants learn how to monitor their own health and work independently as a group. Sessions supported the concept that many factors influence health. Topics included health indicators, chronic disease, nutrition, physical activity, sleep, stress, general health, primary care through the years, medications, supplements, smoking, social supports and how to work effectively as a group. It was mandatory for participants to attend Health School to ensure all participants had the same information, knowledge and engagement.

HANS groups were designed to be participant led and consisted of 8 to 15 people, with support and guidance from NorWest health professionals as needed. Access issues were assessed during the research period and steps taken to mitigate economic challenges to participation, for example, by providing child care or free exercise sessions, and encouraging carpooling. The groups met at least once a month for 1.5- to 2-hour sessions. Some met more often. Each session had required components including: 1) monitor health indicators; 2) prepare a healthy snack; 3) participate in physical activity; 4) share action plan for the month (set a lifestyle goal) - optional; 5) exchange contact information with a "buddy" to do regular check-ins; and 6) socialize.

Thirteen groups were started over a threeyear enrolment period. While some groups succeeded at meeting regularly throughout the research period, others only met briefly and were unable to achieve the group cohesiveness necessary to continue meeting. Nine groups (and their members, $\mathrm{n}=77$ ) were included in this research. Criteria for inclusion were groups that met regularly and participated in at least three of the data collection periods within the time frame of the research $(0,6,12$, 24 months). Seven groups participated in community venues and two were workplace groups. Participant attendance at in-person interviews varied between groups (Table 1).

NorWest staff suggested a variety of reasons for the dropouts, e.g. that the group

TABLE 1

HANS KAI participant attendance for in-person interviews (2010-2015)

\begin{tabular}{llcc} 
& Group type & Enrolment & Participated in 3 or more data collection periods \\
\hline Group 1 & Community & 5 & 5 \\
Group 2 & Community & 7 & 3 \\
Group 3 & Community & 12 & 4 \\
Group 4 & Community & 12 & 7 \\
Group 5 & Workplace & 9 & 8 \\
Group 6 & Community & 5 & 5 \\
Group 7 & Community & 7 & 6 \\
Group 8 & Workplace & 10 & 8 \\
Group 9 & Community & 10 & 7 \\
Total & & 77 & 53 \\
\hline
\end{tabular}

was not a good fit for the individual, changing demographics, returning to work, workplace limitations, changing needs of individuals, time-stressed families, people getting what they needed from the participation and leaving, and people moving.

\section{Data collection}

Data collection was accomplished using a participant survey and individual faceto-face interviews. Participant logbooks tracked selected health indicators but were used inconsistently and did not provide sufficient quantitative data for analysis.

\section{HANS KAI participant survey}

A comprehensive questionnaire, adapting validated instruments from multiple sources, ${ }^{13-19}$ was developed specifically for this study to measure the effects of HANS group participation on the following health-related topics:

- knowledge of diabetes and hypertension;

- nutrition, physical activity and sleep self-assessments;

- smoking status;

- mental health status;

- access to health care providers;

- awareness of community programs and services;

- understanding of how to improve overall health; and

- connectedness to people in the neighbourhood and community.
The project questionnaire, which was developed to maximize content validity and reliability, was edited and modified by a multidisciplinary expert group with experience and expertise in community mobilization and service delivery.

NorWest staff distributed and collected the completed surveys, consisting of baseline surveys when newly enrolled participants attended their first Health School session (Time 1), and follow-up surveys at 6, 12 and 24 months. Data from the completed surveys were entered into a database by NorWest support staff.

\section{Individual interviews}

The researchers interviewed all participants at baseline (Time 1), with follow-up interviews taking place at 6, 12 and 24 months. The baseline interview included two questions about participant perception of factors that had a positive or negative impact on health. The follow-up interviews included the two original questions plus questions intended to elicit feedback about the perceived impact of regular participation in a HANS group and ways to improve HANS KAI. The baseline interviews were documented by the interviewers on paper and then transcribed; however, all follow-up interviews were audio recorded and then transcribed for analysis. The interview questions and schedule are presented in Table 2 .

Baseline interviews (Time 1) were scheduled at the first HANS group meeting of each group following group initiation. Although follow-up interviews were planned at 6 and 12 months after the study began, not all participants could be interviewed at all time intervals due to participant 
TABLE 2

Individual interview questions for HANS KAI participants

\begin{tabular}{|c|c|c|}
\hline Question & $\begin{array}{c}\text { Baseline } \\
\text { interviews }^{\mathrm{a}}\end{array}$ & $\begin{array}{l}\text { Follow-up } \\
\text { interviews }\end{array}$ \\
\hline $\begin{array}{l}\text { 1. In the last } 6 \text { months, what has helped or made it easier to } \\
\text { stay healthy and feel good? }\end{array}$ & $\checkmark$ & $\checkmark$ \\
\hline $\begin{array}{l}\text { 2. In the last } 6 \text { months, what has not helped or made it } \\
\text { harder for you to stay healthy and feel good? }\end{array}$ & $\checkmark$ & $\checkmark$ \\
\hline $\begin{array}{l}\text { 3. Since joining the HANS group, have you received support } \\
\text { from a member of the group? If yes, describe. }\end{array}$ & & $\checkmark$ \\
\hline $\begin{array}{l}\text { 4. Since joining the HANS group, have you provided support } \\
\text { to a member of the group? If yes, describe. }\end{array}$ & & $\checkmark$ \\
\hline $\begin{array}{l}\text { 5. How has being part of a HANS group helped you to } \\
\text { improve your health or stay healthy? }\end{array}$ & & $\checkmark$ \\
\hline 6. What did you like best about the HANS program? & & $\checkmark$ \\
\hline 7. What didn't you like about the HANS program? & & $\checkmark$ \\
\hline 8. What changes would make it better? & & $\checkmark$ \\
\hline
\end{tabular}

${ }^{a}$ Baseline interviews (pre-intervention).

${ }^{b}$ Follow-up interviews at 6, 12 and 24 months.

attendance issues and the inability to arrange meeting times. Consequently, the researchers were unable to obtain interviews at all three time intervals for most participants; however, responses were tracked for 53 individuals who participated in a baseline interview (Time 1) and at least two follow-up interviews (Time 2 and Time 3 ) at either 6,12 or 24 months.

\section{Data analysis}

\section{Survey}

A $t$ test was the test statistic used to perform the pre/post analysis of the survey data with alpha (or $p$ ) set at .05. This analysis approach was modified from the intent-to-treat approach often used in clinical trials. ${ }^{20} \mathrm{~A} z$ test was used to compare the demographic characteristics between the participants who completed the project and those who did not complete the project and were lost to follow-up.

\section{Interviews}

A thematic analysis of all interview responses was conducted. The principal investigators separately analyzed data transcripts of the first 48 baseline interviews and the first 24 follow-up interviews. They then generated initial codes to search for, define and name themes, the outcome of which was a coding template. A principal investigator and research assistant then independently reviewed and coded all transcripts; together they discussed their separate analyses and reached agreement on the interpretation of the data.

\section{Results}

\section{Demographic data}

Client demographics were obtained from 63 participants though not all participants answered every question. Participants were primarily female $(60 / 63)$ with an age range from 20 to 72 years (Figure 1). Of those who answered the question, marital status was equally split between married/ common law (30/63) and single/widowed/divorced/separated (30/63). Thirtyseven percent $(23 / 63)$ had children living at home, $52 \%(33 / 63)$ had no children living at home, and half of the participants (28/63) lived alone. Thirty-five percent had community college/university education, and $41 \%$ were high school graduates. Almost one-third of the participants had lived in their community for at least 25 years (Figure 2), more than one-third were unemployed (Figure 3), and a similar number reported an annual household income of less than $\$ 40,000$ (although $38 \%$ [24/63] of the participants did not answer the last question; Figure 4).

The $z$ test that compared the demographic data, identified statistically significant differences between the participants who completed the project and those who did not complete the project and were lost to follow-up. Those lost to follow-up were less educated and had higher unemployment and lower household incomes.

\section{Pre/post program responses on health-related measures}

The key finding for the pre/post analyses of the survey (Table 3 ) was that the only
FIGURE 1

Age of HANS participants

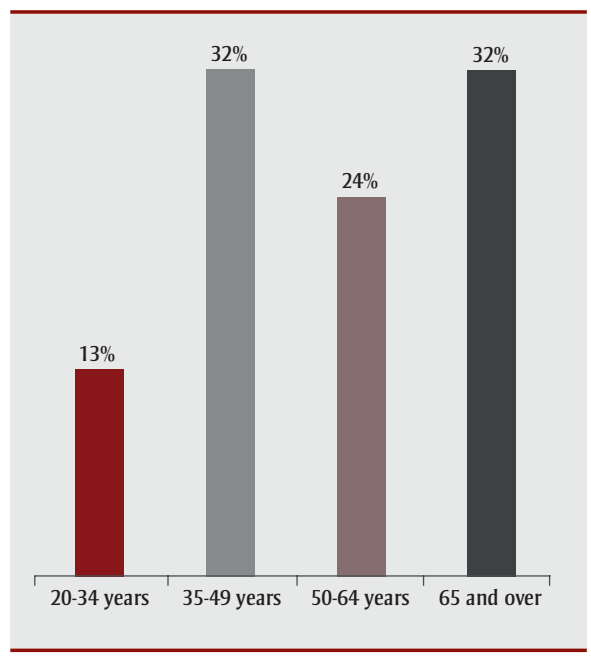

FIGURE 2

Years HANS participants have lived in the community

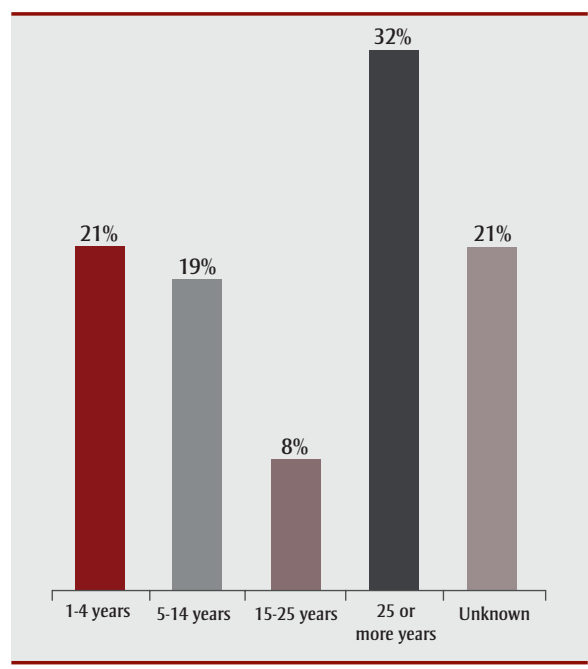

FIGURE 3

Employment status of HANS participants

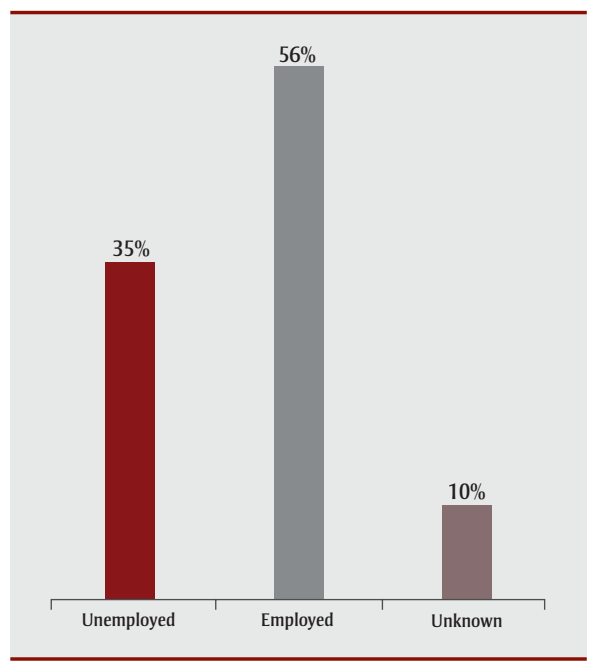


FIGURE 4

Annual household income of HANS participants

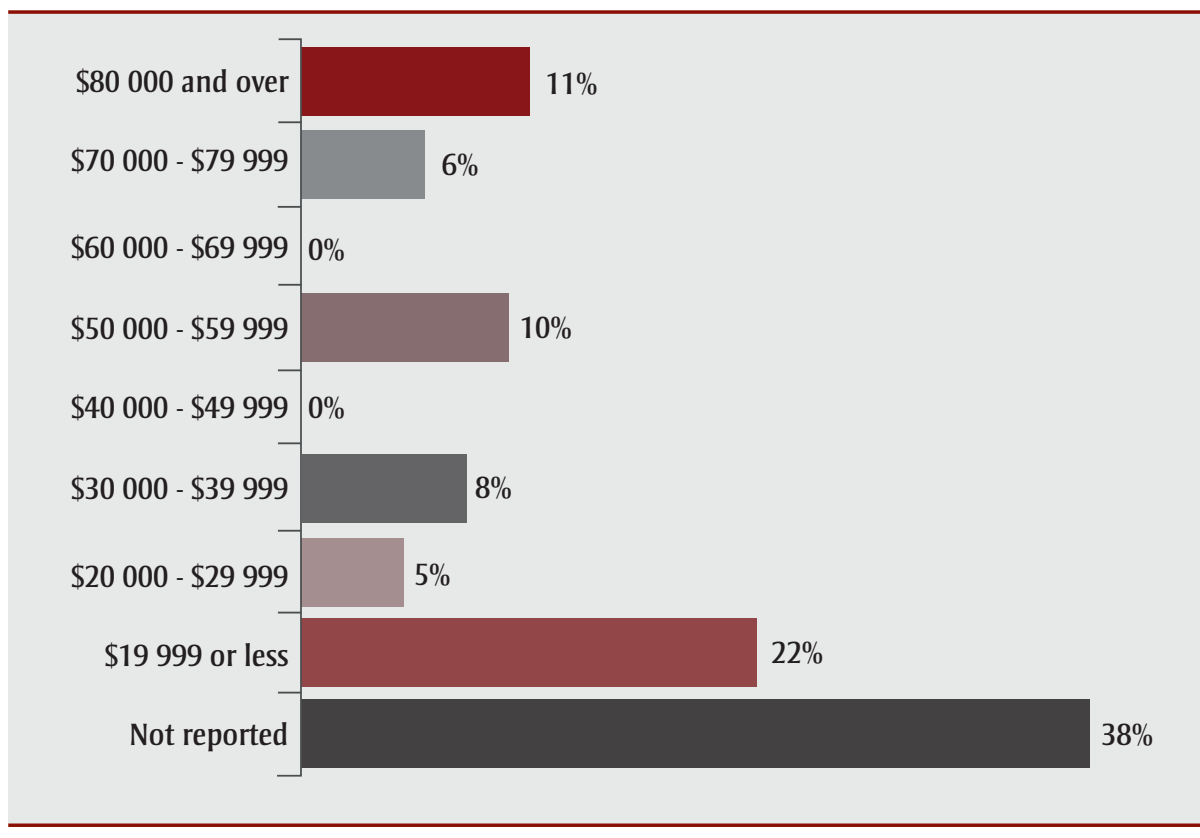

statistically significant improvements from pre- to post-program were in the Mental Health Continuum score. The Mental Health Continuum score assesses wellbeing and establishes results as "flourishing," "moderately mentally healthy" or "languishing." 18

The other post-program health-related measures were not statistically significant.

\section{Findings from individual interviews: factors affecting health}

Participants were asked to identify factors that had a positive or negative impact on their health in the previous six months. The responses were consistent across data collection times, with the only change at 6, 12 and 24 months being increased identification of HANS group participation as a positive impact.

\section{Positive factors affecting health}

Seven factors were identified as having a positive effect on health. Supportive relationships with family and friends was the most frequently mentioned factor having a positive effect. This was consistent across all interview periods. Support from fellow HANS group members was also identified. Physical activity, including both organized activities and leisure activities, and improved nutrition were consistently identified across interview periods as improvinging one's health. Community supports were identified at the beginning (baseline/pre-intervention); however, at subsequent time periods, HANS group participation was the most frequent response regarding community supports. Participants also identified good mental health as having a positive impact on overall health, including being happy at work and experiencing less stress, and having a positive attitude and beliefs. More participants identified the positive impact of access to services over time and, in particular, services at NorWest.

\section{Negative factors affecting health}

Six factors were identified as having a negative impact on health. Compromised mental health/stress was most commonly cited as negatively affecting overall health. Participants decribed being overwhelmed and experiencing work, family or other ticipants identified compromised mental health or stress as having a negative impact on their health. Many participants identified poor nutrition as having a negative impact, including social environments that contributed to increased eating, unhealthy food choices and challenges in maintaining weight or weight gain. However, by Time 3, fewer participants identified poor nutrition as negatively affecting their health. Lack of physical activity, compromised health, lack of time/ work-life balance and unsupportive relationships were also consistently identified stresses. However, by Time 3, fewer par- as negative impacts on health across all time periods. Table 4 groups the factors that had positive or negative health impacts into themes with representative quotes.

\section{Findings from individual interviews: positive impact of HANS participation}

Questions 3 to 6 were intended to identify if involvement in HANS had a positive impact on participants' health and what participants liked about HANS. The different themes that emerged from our analysis are presented pictorially with number of responses (Figure 5) and described more fully below.

\section{Peer support}

The most common responses about the benefits and impact of participation in a HANS group were related to peer support. A much repeated phrase was "we all support each other." Participants described listening to or supporting one another, sharing problems, providing support during a difficult life situation and feeling safe and unjudged. They also described their new friends and sense of community as a result of HANS group participation. One participant recalled how she provided support to another whose child was being bullied at school and helped her pursue it further and "reach a resolution." Some described giving or receiving rides to the group meetings or to medical appointments, or sharing resources that might be helpful. Others described reaching out to another outside the group meeting and keeping connected between meetings through regular phone contact, emails, texts, walks or coffee outings.

\section{Learning/knowledge}

Participants described how they received information about health-related topics and healthy choices from the Health School, guest speakers and each other. They identified the impact of the new skills they had learned, including chair exercises; measurements (e.g. blood sugar, blood pressure); Zumba; cooking; and meditation.

\section{Reported behaviour change}

Sixty-six percent of the participants were able to describe specific behaviour changes as a result of participating in the HANS group. Behaviour changes were primarily in the areas of nutrition and exercise, and in other areas such as stress and weight, blood sugar and/or blood pressure 
TABLE 3

Analysis of HANS participants' pre/post-program responses on health-related measures

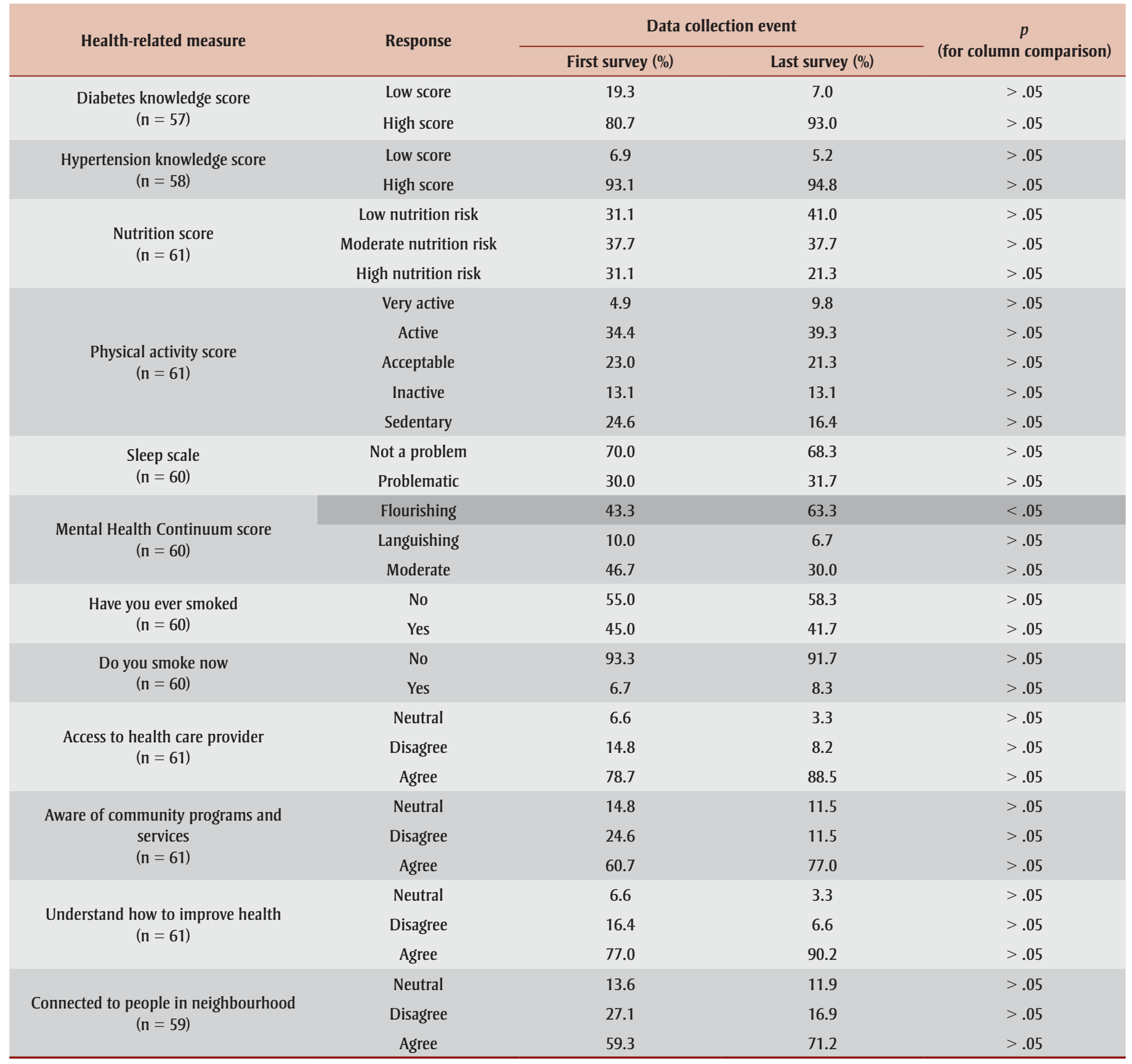

management. Participants also described the positive aspects of goal setting and other changes. Additionally, participants described how learning from the HANS group had extended farther with positive impacts on other members of their families.

\section{Inspiration/motivation/accountability}

Participants described how participation in a HANS group has had an impact on their health through inspiration, motivation or accountability. Participants also described their desire to share the benefits of HANS group participation by encouraging others to join or sharing the information they had received in the group.

\section{Monitoring indicators}

Participants identified that taking responsibility for monitoring their own health indicators in their logbooks was empowering, reassuring and motivating. They appreciated being able to do their own monitoring, and these measures also spurred action to seek medical support if needed (e.g. "Because I discovered high blood pressure at HANS KAI I went to see my doctor and it is now under control”).

\section{Overcoming social isolation}

Some participants identified that participation in a HANS group contributed to their sense of belonging and motivated them to "get out."

\section{Access to services}

Participants noted that their involvement in HANS provided a gateway to access 
TABLE 4

Positive and negative factors affecting health with representative quotes from HANS participants

\begin{tabular}{|c|c|c|}
\hline \multicolumn{2}{|c|}{ Factors impacting health } & Quotes \\
\hline \multirow{7}{*}{$\begin{array}{l}\text { Positive } \\
\text { factors }\end{array}$} & Supportive relationships & $\begin{array}{l}\text { "a very supportive family"; "my husband"; "my kids"; "my friends"; "HANS members have helped"; } \\
\text { "[they] play a good role in it"; "love talking to them and some are good friends and we socialize outside } \\
\text { HANS KAI so it's good to talk out things and share" }\end{array}$ \\
\hline & Physical activity & "regular exercise”; “exercise class 3x per week”; “Hip Hop”; “Zumba”; "walking”; "playing with kids”; "yoga” \\
\hline & Improved nutrition & "change in diet"; "eating healthy foods"; "eating better" \\
\hline & Community supports & "meeting with other people"; "interacting with the [HANS] group helps me ... [the] relationships we have built" \\
\hline & Good mental health & “love my work”; “changes at my work”; “quit work”; “learning to cope with issues”; “less stress” \\
\hline & Positive attitude and beliefs & "accountability to the group"; “motivated when [I’m] with others"; "self reliant" \\
\hline & Access to services & $\begin{array}{l}\text { [Access to] “doctor"; “dietician"; "psychologist”; "nurse practitioner”; "I have a team now”; "all kinds of } \\
\text { [NorWest] specialists" }\end{array}$ \\
\hline \multirow{6}{*}{$\begin{array}{l}\text { Negative } \\
\text { factors }\end{array}$} & Compromised mental health / stress & $\begin{array}{l}\text { "I feel overwhelmed"; "busy schedules"; "work responsibities and issues with ... family and friends"; } \\
\text { "lack of support ... [at work]"; "I have a very stressful job"; "I work too many hours ... have too many } \\
\text { responsibilities"; "family life is always stressful”; "my ... [son, daughter, husband, mom, children]"; } \\
\text { "death in the family" }\end{array}$ \\
\hline & Poor nutrition & $\begin{array}{l}\text { "attending ... gatherings"; "eating out"; "the holidays"; "bad eating habits"; "[we eat unhealthy] when I } \\
\text { don't have time"; "being overweight"; }\end{array}$ \\
\hline & Lack of physical activity & “not enough time”; “don’t make time [to exercise]”; “pain from injury”; “the weather” \\
\hline & Compromised health & "heart condition”; “diabetes”; “arthritis”; “pain” \\
\hline & Lack of time / work-life balance & “work demands”; “family demands”; “just been really busy ... not much time for myself” \\
\hline & Unsupportive relationships & “not having enough family support”; "family has made it harder" \\
\hline
\end{tabular}

services: services provided by NorWest, encouragement to see health care providers regularly and information about other services in the community.

Table 5 summarizes the positive health impacts of HANS participation with representative quotes.

FIGURE 5

Benefits of HANS participation (\# responses)

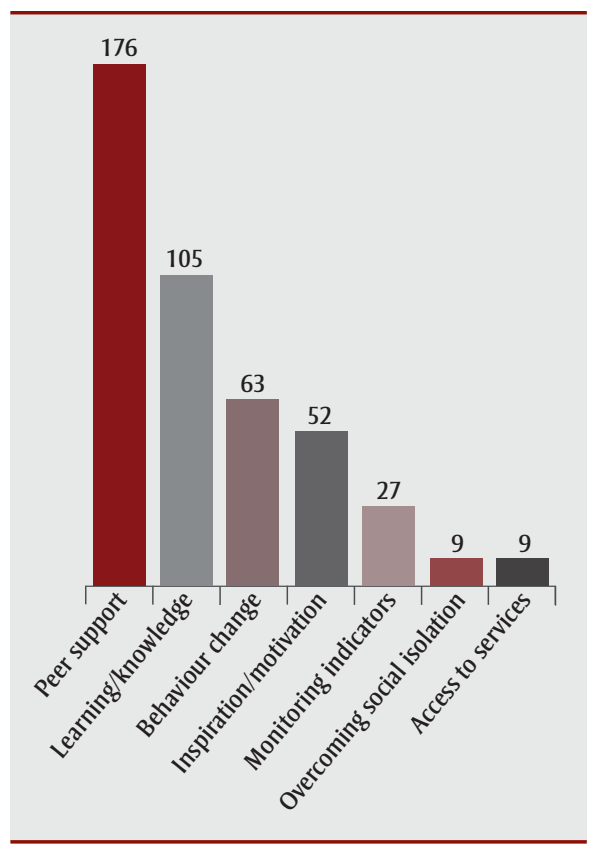

Findings from individual interviews: recommendations for improving HANS groups

Questions 7 and 8 were intended to gather participant feedback on how to improve HANS. Participants identified three main areas for improvement.

\section{Meeting format}

Participants described issues such as frequency and duration but did not agree on optimal frequency and duration. Some identified the need to have additional group members.

\section{Leadership/structure/organization}

HANS groups are participant led, but the most common feedback about improvement was for more leadership and structure. In most groups a leader emerged; however, not all participants shared the leadership role. Groups were destabilized when the leader was no longer available to lead, and groups became smaller due to attrition and changes in meeting dates and/or locations. Some groups were more successful than others in identifying the types of education sessions they wanted. Participants wanted more interaction with their NorWest contact person and suggested a number of program improvements such as regular meetings with planned agendas.

\section{Access}

Consistent attendance at HANS groups was a challenge for some participants. Participants identified busy schedules and competing responsibilities as well as issues such as transportation and meeting location. Workplace groups had particular challenges with the meeting times.

Table 6 summarizes the suggested improvements to HANS KAI with representative quotes from participants.

\section{Discussion}

The purpose of this study was to determine if structured peer-led community groups could be successfully initiated within an urban Canadian context and have a positive impact on the health of participants. A meta-analysis of 148 studies found that having supportive relationships was related to decreased mortality risks. $^{21}$ Berkman and Glass $^{22}$ identified that adults who are socially isolated have a two- to five-fold higher death rate than others. While peer support has been used in health promotion initiatives, it has been more widely used in disease-specific health promotion initiatives. ${ }^{23-25}$ 
TABLE 5

Positive health impacts of HANS particpation and representative quotes

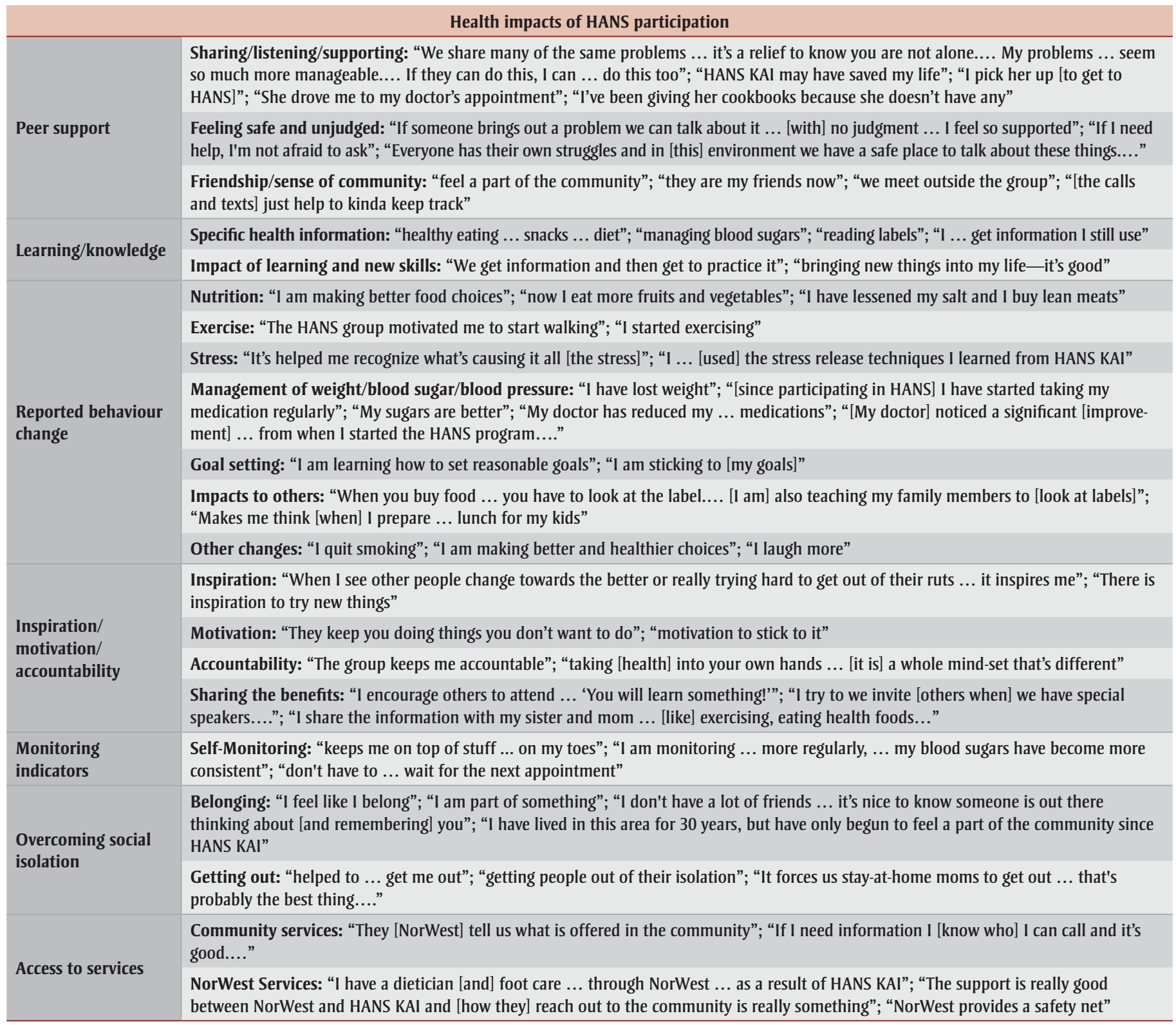

Our findings suggest that there were benefits to participation in a HANS group, including peer support, learning/knowledge, behaviour change, inspiration/motivation/accountability, overcoming social isolation and increased access to primary care and other health-related services. These findings are congruent with previous research undertaken in the area of peer support groups and their impact on health. Peer-led approaches that contribute to community "belonging" had a positive effect on the "most prominent health behaviours (exercise, weight loss and improved diet). ${ }^{26, p .277}$ A systematic review of 25 randomized controlled trials assessing health-related behaviour change in older adults concluded that peer-based interventions contributed to positive healthrelated behaviour change such as increased physical activity, decreased smoking, increased condom use and increased completion of advance directives. ${ }^{27}$ While most community-based peer support initiatives have focussed on a specific health behaviour, others were implemented to create social support or social networks to prevent social isolation. ${ }^{2}$ In a 2015 study of a community-based program developed to create peer support networks, the major themes that emerged were creation of social networks, enhancement of well-being and provision of empowering services. ${ }^{28}$ Peer support has also been found to increase access to primary care services, including health information, community programs and support services. ${ }^{24,26,28-36}$ In addition, peer-based interventions have been reported to bring about shared achievement through doing, providing role models and sharing knowledge, which in turn brought about satisfaction, self-confidence and acceptance among group members. ${ }^{24,36-41}$

Where this research adds to the literature is in the area of support groups that address interrelated chronic disease prevention 
TABLE 6

Participants' suggestions to improve HANS KAI and representative quotes

\begin{tabular}{|c|c|}
\hline \multicolumn{2}{|r|}{ Improving HANS KAI } \\
\hline \multirow{2}{*}{ Meeting format } & Frequency/duration: "I wish we could meet more often"; "I think it should be longer"; "I would rather meet [just] once per month" \\
\hline & Membership: "Our numbers are not as strong as we want it to be"; "If we could have a couple more members that would be nice" \\
\hline \multirow{3}{*}{$\begin{array}{l}\text { Leadership/structure/ } \\
\text { orgáanization }\end{array}$} & $\begin{array}{l}\text { Leadership: "Not having a lead person may work in Japan but I don't think it works here"; "With rotating leaders there is no one really } \\
\text { [coordinating] it"; "We have___ she keeps everything together. It would be hard if she wasn't [here]"; "We had ... a person who took more } \\
\text { charge [who] left and since then it pretty much fell apart" }\end{array}$ \\
\hline & $\begin{array}{l}\text { Structure: "We are getting different speakers which is great"; "I wish [the presenters were] better prepared"; "more topics"; "more } \\
\text { group discussions"; "more exercise classes"; "return funding for snacks" }\end{array}$ \\
\hline & $\begin{array}{l}\text { Organization: "I would put a strong emphasis on ... providing more structure and more support from the NorWest staff contact person; } \\
\text { "sometimes they just fly in and fly out"; "[need] a regular check" }\end{array}$ \\
\hline Access & $\begin{array}{l}\text { Access: "finding the time"; "distance I have to come to go to it"; "I can't attend during the day"; "use handi transit ... sometimes I don't } \\
\text { have enough for extra tickets"; "busy schedules"; "it's ... after work" }\end{array}$ \\
\hline
\end{tabular}

behaviours (healthy eating, regular physical activity, monitoring indicators and social support) within a model of peer support and their impact on health versus those that focus on a single chronic disease or condition and a related specific health behaviour.

Although the benefits of peer support are well documented in the literature, it cannot be said that the empirical evidence is unequivocal on this issue. Webel et al. ${ }^{27}$ conducted a systematic review of the effectiveness of peer-based interventions for specific behaviour change and concluded that the evidence was mixed. Some interventions were effective (physical activity, smoking and condom use) while others were not (breastfeeding, medication adherence and women's health screening).

The findings of this study are similar. Quantitative results from the participant survey show that participation in a HANS group resulted in statistically significant improvement only in mental health scores and resulted in possible positive trends in other health-related measures. However, the qualitative results from thematic analysis of the in-person interviews identified that HANS group participation had a positive impact on participants' health primarily through peer support and through learning/increased knowledge. Additionally, $66 \%$ of the participants reported a behaviour change even though there was no statistically significant change identified in the quantitative data. This could be related to the way the behaviour change questions were presented in the survey or could indicate that open-ended qualitative methods may be a better way of eliciting behaviour change information. An unexpected finding was the absence of reported incomerelated stress (which the researchers had anticipated from the open-ended question "What has not helped or made it harder for you to stay healthy and feel good?") despite the proportion of participants being unemployed or in a lower-income group.

In summary, HANS KAI groups appear to have a significant positive impact on participants' mental health as identified in both the quantitative and the qualitative findings. Additionally, participants experienced increased support and connectedness, which may generate positive effects in some areas of health including participant-reported behaviour changes. It is less clear whether HANS KAI improves measurable indicators such as blood sugar, blood pressure, weight and waist circumference. More research is needed to identify if HANS participation has an impact on these measurable indicators over time.

\section{Limitations}

There were a number of limitations of this study. Our sample was recruited from one (Canadian) jurisdiction and was primarily female. Lack of male participation may be attributable to male hesitance to seek assistance for health issues, especially related to preventive interventions, but presents an opportunity to consider how to include more men in the intervention. These may limit the transferability of findings. In addition, our sample was not large; the findings are based on only groups that met regularly and on selfreported feedback, although the qualitative methodology that was used provided indepth information that could compensate for this limitation. We were unable to compare the measurable indicators of blood sugar, blood pressure, weight and waist circumference over time due to incomplete logbooks that tracked these self-measured health indicators. Selfreported health behaviour changes (general and specific) may not capture true behaviour change and may be subject to recall or social desirability biases. Additionally, four groups that started were unable to continue for a variety of reasons (e.g. loss of interest, struggle to schedule meeting times). Participants missed meetings when interviews were scheduled, were unavailable or lost to follow-up, and there were challenges with regular participant attendance. Similar to this research, Gustavson et al. identified the challenge of high attrition rates in public health intervention research (30-70\%), which may impact the generalizability of the findings. ${ }^{42}$ Attempts were made to contact those who stopped participating; however, researchers were only able to conduct a few exit interviews.

There were statistical differences between the demographics of the research participants and those lost to follow-up, and the lack of data from dropouts may have affected the findings of the study. The peer support model used in this research was intentionally peer-led where all participants were peers and guidance and support was provided from NorWest health professionals. However, the most common feedback about improving HANS were requests for more leadership and more structure. 
While peer support may provide knowledge, a sense of connection and improvements in self-care, there are other methods, both individual and group-related interventions, that may also work, and health professionals need to understand which might be the best match for a client. ${ }^{43-44}$ Peer support groups to improve health may not be the right fit for or be effective for everyone, and the peer-led model with the perceived lack of supports may have contributed to the attrition rate.

Health promotion literature has identified that interventions focussed on lifestyle or behaviour change at the individual level may have limited long-term effects as "health behaviours are influenced by many competing factors: cultural pressures, health literacy, health inequalities, mental capacity, genetic predisposition and, in the case of smoking and alcohol, addiction to a substance." ${ }^{45, p .1}$ At the same time, a 12- to 24-month intervention may not be long enough to know about the sustained health effects of HANS group participation.

\section{Conclusion}

As the focus of health care changes from treating disease to promoting health, the use of peer support is becoming more common not only in the discipline of health but also in behavioural science. ${ }^{2}$ HANS KAI participation, embedded in a model of peer support, is intended to support health using a variety of health promotion interventions such as education, action, access to services and empowerment. This community-based research is driven by a need to identify innovative ways to address chronic disease prevention and management in a community challenged with interrelated factors (social determinants of health) such as lower education and income, social isolation and lack of access to health and recreation services.

This research used a participatory design between NorWest and the researchers, and included direction and feedback from a community board and community residents. The duration of this research project followed individuals over a period of up to 24 months. Participation in a HANS group is intended to be for the long term with participants and groups continuing well after the life of the research project. This may be an improvement over other chronic disease prevention interventions of prescribed length (6-12 weeks) or around a single chronic disease or behaviour change.

The findings of this research suggest that HANS KAI proved to be an effective intervention to realize statistically significant improvements in the area of mental health. The findings from the qualitative analysis also suggest that there were benefits to participation in a HANS group, including peer support, learning/knowledge, behaviour change, inspiration/motivation/accountability, overcoming social isolation and increased access to primary care and other health-related services.

While further research will be required to validate these findings, it appears that the HANS KAI approach, which goes beyond focussing on individual behaviour change and considers the importance of community, may be effective for creating environments that empower community members to support each other while promoting healthy lifestyle choices and detecting early changes in health status.

\section{Acknowledǵments}

Funding was provided by the NorWest Co-op Community Health Centre. The authors would like to acknowledge the support of the NorWest staff and all the participants of the HANS KAI groups who participated in the research. We would also like to acknowledge the support and input provided by the NorWest HANS KAI organizers, Nancy Heinrichs (Executive Director), Michelle Kirkbride (Community Development Team Coordinator), Shannon Milks (Primary Care Coordinator) and Mike Sadlowski (Health Promotion Specialist); Dr. Benita Cohen (qualitative research advisor); Dr. Nawal Lutfiyya (data analyst - quantitative data); Dr. Lawrence Elliot (quantitative research advisor); Kristy Boyko, Kate Hodgson and Adebusola Adekoya (research assistance); and the Manitoba Centre for Nursing \& Health Research.

\section{Conflicts of interest}

The authors have no conflicts of interest.

\section{Authors' contributions and statement}

AH and HW worked closely with the HANS KAI advisory group from the NorWest Co-op Community Health Centre to conceptualize, plan and conduct the research. Additional support was obtained from contributors as described in the acknowledgements. HW had a primary role in conceptualizing and executing the project plan, and $\mathrm{AH}$ had the primary role in data collection and analysis as well as drafting of the preliminary report. Both authors read and approved the final manuscript.

The content and views expressed in this article are those of the authors and do not necessarily reflect those of the Government of Canada.

\section{References}

1. Mead S, Hilton D, Curtis L. Peer support: a theoretical perspective. Psychiatr Rehabil J. 2001;25(2):134-41.

2. Dennis CL. Peer support within a health care context: a concept analysis. Int J Nurs Stud. 2003;40(3): 321-32.

3. Dennis CL. The process of developing and implementing a telephone-based peer support program for postpartum depression: evidence from two randomized controlled trials. Trials. 2014; 15(1):131. doi: 10.1186/1745-6215-15131.

4. Thomas GN, Macfarlane DJ, Guo B, et al. Health promotion in older Chinese: a 12-month cluster randomized controlled trial of pedometry and "peer support". Med Sci Sports Exerc. 2012;44(6):1157-66. doi: 10.1249/MSS .0b013e318244314a.

5. Ford P, Clifford A, Gussy K, et al. A systematic review of peer-support programs for smoking cessation in disadvantaged groups. Int $\mathrm{J}$ Environ Res Public Health. 2013;10:5507-22. doi: 10.3390/ijerph10115507.

6. Panayotof-Schaan L. An overview of health co-operatives: a case study perspective using Canadian and international examples [Internet]. Victoria, BC: British Columbia Institute for Co-operative Studies; 2009 [cited 27 Mar 2017]. Available from: http:// planh.ca/sites/default/files/panayotof -schaan_healthcooperatives.pdf

7. Girard JP, Restakis J. To Life! Japan’s model of co-operative health care \& what it means for Canada. Making Waves. 2008;19(1):5-8. 
8. Bandura A. Social learning theory. Englewood Cliffs, NJ: Prentice Hall; 1977

9. Zimmerman MA. Empowerment theory. In: Rappaport J, Seidman E, editors. Handbook of community psychology. New York: Kluwer Academy / Plenum Publishers; 2000. p 43-63.

10. Winnipeg Regional Health Authority; George and Fay Yee Centre for Healthcare Innovation, Evaluation Platform. Inkster community area profile, 2015 [Internet]. Winnipeg (MB): Winnipeg Regional Health Authority; 2015 [cited 27 Mar 2017]. Available from: http://www.wrha.mb.ca/research /cha2014/files/Inkster.pdf

11. Kaplan and Associates. Inkster in action report. [Winnipeg (MB): Kaplan and Associates]; 2008.

12. Cresswell J, Klassen A, Clarke V, et al. Best practices for mixed methods research in the health sciences [Internet]. [Washington]: National Institutes of Health, Office of Behavioral and Social Sciences Research (US); 2011 [cited 27 Mar 2017]. Available from: https://www.nursing.virginia.edu /media/Best_Practices_for_Mixed_ Methods_Research.pdf

13. Government of Manitoba, Manitoba in Motion. Physical activity self-assessment. Winnipeg (MB): Government of Manitoba; 2010.

14. Harland Gregoire MJ, Chow S, Spooner GR, et al. A screening instrument to identify adults with nutritional risks in a family medical practice. Can J Diet Pract Res. 1999;60(4)205-11.

15. Government of Manitoba, Tobacco Control \& Cessation. Commit to quit self-assessment. Winnipeg (MB): Government of Manitoba; 2010.

16. Williams MV, Baker DW, Parker RM, et al. Relationship of functional health literacy to patients' knowledge of their chronic disease. A study of patients with hypertension and diabetes. Arch Intern Med. 1998;158:166-72. doi: 10.1001/archinte.158.2.166.

17. Hayes R, Stewart A. Sleep measures. In: Stewart A, Ware J, editors. Measuring functioning and well-being: the Medical Outcomes Study approach. Durham (NC): Duke University; 1992. p. 235-59.
18. Keyes C. Brief description of the mental health continuum short form (MHC-SF) [Internet]. Atlanta (GA): [Emory University]; 2009 [cited 27 Mar 2017]. Available from: https://www .aacu.org/sites/default/files/MHC -SFEnglish.pdf

19. Ware JE Jr, Sherbourne CD. The MOS 36-item short-form health survey (SF36): I. Conceptual framework and item selection. Med Care. 1992;30(6): 473-83.

20. Gupta SK. Intention-to-treat concept: a review. Perspect Clin Res. 2011;2(3): 109-12.doi: 10.4103/2229-3485.83221.

21. Holt-Lunstad J, Smith T, Layton JB. Social relationships and mortality risk: a meta-analytic review. PLoS Med. 2010;7(7):e1000316. doi: 10.1371/journal .pmed.1000316.

22. Berkman LF, Glass TA. Social integration, social networks, social support, and health. In: Berkman LF, Kawachi I, editors. Social epidemiology. New York: Oxford University Press, 2000. p. 137-73.

23. Bagnall AM, South J, Hulme C, et al. A systematic review of the effectiveness and cost-effectiveness of peer education and peer support in prisons. BMC Public Health. 2015;15:290. doi: 10.1186/s12889-015-1584-X.

24. Woolhouse S, Cooper E, Pickard A. "It gives me a sense of belonging": providing integrated health care and treatment to people with HCV engaged in a psycho-educational support group. Int J Drug Policy. 2013;24(6):550-7. doi: 10.1016/j.drugpo.2013.05.018.

25. Zhong X, Wang Z, Fisher EB, et al. Peer support for diabetes management in primary care and community settings in Anhui Province, China. Ann Fam Med. 2015;13 Suppl 1:S50-8. doi: 10.1370/afm.1799.

26. Hystad P, Carpiano RM. Sense of community-belonging and health-behaviour change in Canada. J Epidemiol Community Health. 2010;66(3):277-83. doi: 10.1136/jech.2009.103556.

27. Webel AR, Okonsky J, Trompeta J, et al. A systematic review of the effectiveness of peer-based interventions on health-related behaviors in adults. Am J Public Health. 2010;100(2):24753. doi: 10.2105/AJPH.2008.149419.
28. Liamputtong P, Koh L, Wollersheim D, et al. Peer support groups, mobile phones and refugee women in Melbourne. Health Promot Int. 2016; 31(3):715-24. doi: 10.1093/heapro /dav015.

29. Aschbrenner KA, Naslund JA, Shevenell $M$, et al. Feasibility of behavioral weight loss treatment enhanced with peer support and mobile health technology for individuals with serious mental illness. Psychiatr Q. 2016;87(3): 401-15. doi: 10.1007/s11126-015-9395-X.

30. Coşkun A, Karakaya E. Supporting safe motherhood services in Diyarbakir: a community-based distribution project. Matern Child Health J. 2013; 17(6):977-88. doi: 10.1007/s10995-012 -1102-z.

31. Crawford S, Bath N. Peer support models for people with a history of injecting drug use undertaking assessment and treatment for hepatitis C virus infection. Clin Infect Dis. 2013;57 Suppl 2:S75-9. doi: 10.1093/cid/cit297.

32. Hanson LC, Armstrong TD, Green MA, et al. Circles of care: development and initial evaluation of a peer support model for African Americans with advanced cancer. Health Educ Behav. 2013;40(5):536-43. doi: 10.1177 /1090198112461252.

33. Hanson LC, Green MA, Hayes M, et al. Circles of care: implementation and evaluation of support teams for African Americans with cancer. Health Educ Behav. 2014;41(3):291-8. doi: 10.1177 /1090198113512127.

34. Mason K, Dodd Z, Sockalingam S, et al. Beyond viral response: a prospective evaluation of a community-based, multi-disciplinary, peer-driven model of $\mathrm{HCV}$ treatment and support. Int J Drug Policy. 2015;26(10):1007-13. doi: 10.1016/j.drugpo.2015.04.012.

35. Rempel LA, Moore KC. Peer-led prenatal breast-feeding education: a viable alternative to nurse-led education. Midwifery. 2012;28(1):73-9. doi: 10.1016 /j.midw.2010.11.005.

36. Swarbrick MA. Integrated care: wellness-oriented peer approaches: a key ingredient for integrated care. Psychiatr Serv. 2013;64(8):723-6. doi: 10.1176/appi.ps.201300144. 
37. Ashing-Giwa K, Tapp C, Rosales M, et al. Peer-based models of supportive care: the impact of peer support groups in African American breast cancer survivors. Oncol Nurs Forum. 2012;39(6):585-91. doi: 10.1188/12 .ONF.585-591.

38. Coniglio FD, Hancock N, Ellis LA. Peer support within Clubhouse: a grounded theory study. Community Ment Health J. 2010;48(2):153-60. doi: $10.1007 / \mathrm{s} 10597-010-9358-5$.

39. Lu Q, You J, Man J, et al. Evaluating a culturally tailored peer-mentoring and education pilot intervention among Chinese breast cancer survivors using a mixed-methods approach. Oncol Nurs Forum. 2014;41(6):629-37. doi: 10.1188/14.ONF.629-637.

40. Raine P. Promoting breast-feeding in a deprived area: the influence of a peer support initiative. Health Soc Care Community. 2003;11(6):463-9. doi: 10.1046/j.1365-2524.2003.00449.x.

41. Repper J, Watson E. A year of peer support in Nottingham: lessons learned. Journal of Mental Health Training, Education and Practice. 2012;7(2):708. doi: 10.1108/17556221211236466.

42. Gustavson K, von Soest T, Karevold E, et al. Attrition and generalizability in longitudinal studies: findings from a 15-year population-based study and a Monte Carlo simulation study. BMC Public Health. 2012;12:918. doi: 10.1186/1471-2458-12-918.

43. Sav A, McMillan Sara, Kelly F, et al. Consumer health organisations for chronic conditions: why do some people access them and others don't? Prim Health Care Res Dev. 2014;15:112. doi: $10.1017 /$ S1463423614000036.

44. Lawn S, Schoo A. Supporting self-management of chronic health conditions: common approaches. Patient Educ Couns. 2010;80(2):205-11. doi: 10.1016/j.pec.2009.10.006.

45. Thirlaway K, Davies L. Lifestyle behaviours and personal responsibility for health. eLS [Internet]. 2013 Sep [27 Mar 2017]. doi: 10.1002/9780470015902 .a0025159/abstract. 